\title{
Analysis of cut marks on ancient human remains using confocal profilometer
}

\begin{abstract}
Different types of superficial bone marks are present on human remains and often are difficult to interpret. Diagenetic processes, vascularization owns marks or human action are some of them. To discriminate the different kinds of marks that can be found on ancient remains has always been a challenge in an anthropological study. The aim of this project is to valorate the use of confocal profilometry (Leica DCM 3D), to discriminate different kinds of marks (butchery related, taphonomic, vascular, and suture related). Macroscopic and microscopic differences have been found between all groups of marks. Whereas taphonomic and butchery related marks had been previously described, this work has shown depth and morphology to be the main characteristics in vascular marks, with aggrupation and location near a suture being characteristic in suture marks. A new method of study has been proposed that is aimed at differentiating trampling and taphonomic marks from butchery related marks. Butchery marks display a greater depth and complexity than taphonomic marks, with both parameters being the only ones displaying significant differences between groups. Despite this, depth and complexity appear as when a discriminant function is generated. Confocal profilometry techniques provide three-dimensional information of the sample without any manipulation, and allow quantitative information to be obtained on the studied volume. In addition, the stitching system allows large areas to be analysed in order to provide information representative of the sample. This new technique, combined with the conventional techniques used in the field of anthropology, will allow a very accurate identification of different types of marks on human remains in the field of anthropology.
\end{abstract}

Volume 5 Issue I - 2020

\author{
Xavier Casanova,' Mònica Roldán, ${ }^{2}$ M Eulàlia \\ Subirà ${ }^{3}$ \\ 'Departament de Biologia Animal, Biological Anthropology, Plant \\ Biology and Ecology Unit,Autonomous University of Barcelona, \\ Spain \\ ${ }^{2}$ Confocal Microscopy Unit, Pathological Anatomy Service, \\ Pediatric Institute for Rare Diseases, Sant Joan de Déu Hospital, \\ Spain \\ ${ }^{3}$ Department of Animal Biology, GREAB (Research Group \\ Applied to Biological Anthropology), Unit of Biological \\ Anthropology, Plant Biology and Ecology, Autonomous \\ University of Barcelona, Spain
}

\section{Correspondence: M Eulàlia Subirà, Biological Anthropology} Unit, Department of Animal Biology, Plant Biology and Ecology, Autonomous University of Barcelona, 08193-Bellaterra, Barcelona, Spain, Tel +34 93581 1860, Fax 34 9358 I 1321, EmailEulalia.Subra@uab.cat,monica.rolan@uab.es

Received: October 28, 2019 | Published: February 10, 2020

Keywords: confocal profilometer, human remains, butchery marks, taphonomic marks. iberian, nailed skulls

\section{Introduction}

In the decade of the eighties of the last century the studies of the different marks observed in the surface of the fauna bones are generalized to establish their nature. One of the most studied aspects is the intentional origin of the marks in order to carry out a prehistoric reconstruction of the practices of desilling and cutting of the hunted pieces and thus be able to establish the subsistence strategies of the first hominids. ${ }^{1-3}$ This type of marks is not exclusive to the faunal remains and is also observed in human remains with a diverse origin. Thus, they can be caused by cutting practices, but also other practices, some with possible -careful of patients, aggression, attacks, or treatment practices corpse in a funeral ritual. In all these practices all marks would have an anthropic origin presenting a great variability according to their origin but also according to the technique applied in the specific chronological moment in which they occurred. However, the anthropic marks on the bones is not exclusive, there are marks on the surface of the bones reflecting the taphonomic alterations that the passage of time has left in the form of marks on its surface. Therefore, the causes of the marks that can appear on the surface of the bone are diverse and not all of them are due to anthropic action, nor are they made only in the fauna, but they also occur in human remains.

It is necessary to find new techniques that help in the reconstruction and interpretation of the circumstances and characteristics in which they occurred, either individually or collectively. Most studies have focused on recognizing their origin in fauna remains, their location and nature, focusing on the simultaneous analysis of taphonomic markings, with butchery markings on wildlife remains, most of them being studies based on experimentation. First, the studies contemplated visual morphological description of the expert identification with some measurement in faunal remains for the interest of know the first evidence of humans as a result of their skinning, dismembering, or fleshing. ${ }^{1-5}$ Posterior analysis incorporate application of binocular microscopes with high resolution images ${ }^{2,6-10}$ or including scanning electron microscope (SEM), that allow to accurate the results and differentiate cut marks produced by a range of materials as lithic, metal or Wood. ${ }^{11,12}$ Recently the application of 3D analysis of geometric morphometry permit analyse the measurements and angles, and then identified the object. ${ }^{13,14}$ These activities, as have been demonstrated by some authors, have also been applied to human remains for many reasons as cannibalism in early Europe ${ }^{15-17}$ or cultural treatment of the death as the nailed skulls of the Iberian Culture ${ }^{18,19}$ or the skull trophies from the Torre Strait Islands..$^{20}$ Unfortunately, the features of all marks can easily be confused with taphonomic ones. Many authors ${ }^{6,21}$ have focused their investigation to recognize some kind of the marks using macroscopic and microscopic description of characteristics. ${ }^{22}$ Number of marks per area studied, location, straightness, trajectory, and shape (angles, depth) have shown to be the best discriminators by Olsen and Shipman, ${ }^{6}$ Bello and Soligo, ${ }^{23}$ and Domínguez-Rodrigo et al. ${ }^{21}$

In most cases, interest in wildlife studies focused on identifying the agent that produced the markings and, therefore, on whether they were due to butchery related marks or taphonomic waves. 
The studies were initially performed with the naked eye, whereas microscopy techniques were later applied. An example would be the studies of Bello et al..$^{23}$ and Domínguez-Rodrigo et al. ${ }^{21}$ who describe the two types of markings from use of classical light microscope as: Taphonomic marks: These kinds of marks are irregular in both straightness and depth parameters, and do not have any particular direction on the surface of the bone. Butchery marks: Located in groups on areas where the muscle is attached to the bone. These kinds of marks are usually of short length, a characteristic V-shape, straight path, great depth, and their direction tends to follow the insertion of the muscle.

However, the depth of focus provided by the optics is typically shallower than the specimen's full depth, thereby leaving only a portion of the surface focused and becoming a disadvantage. Despite the tradition of these techniques, other methodologies of high resolution, such as Scanning Electron Microscopy (SEM) have aimed to improve the results, revealing 3D information, ${ }^{24}$ although the major drawback of this approach is its sensibility to the accurate determination of the calibration data ${ }^{25}$ and provide a more objective evaluation of the metrical characteristics. ${ }^{26}$

More recently, the use of new improved topographical techniques have allowed for the processing of three-dimensional reconstructions, ${ }^{27,28}$ then features of microtopography of bone surface can be measured: cross-sectional shape, depth, shoulder height and others. ${ }^{26}$ The generation of these three-dimensional models is a laborious and time-consuming work. ${ }^{27}$ Consequently, when quantitative 3D surface analysis is needed alternate methods have to be applied, such as Focus Variation Microscopy, or Confocal Scanning Microscopy. Focus-Variation microscopy allows images to be acquired at different focal planes, but is not confocal images, i.e., focused and unfocused images are captured using special software that allows three-dimensional images to be obtained. This technology is suitable when working at low magnification with samples showing more texture and contrast. However, for samples that require higher resolution and accuracy, it is necessary to use confocal microscopy (personal communication of Leica Microsystems technical). Confocal Profilometer (Leica DCM 3D) is presented as a non-tactile, fast, and precise method, with a great potential for allowing a quantitative approach for the study of bone marks. This technology offers several advantages over conventional wide-field optical microscopy, including the ability to control depth of field, elimination or reduction of background information away from the focal plane, and the capability to collect serial optical sections from thick specimens. Confocal profilers measure the surface height of smooth to very rough surfaces, with spatial sampling as low as $0.10 \mu \mathrm{m}$ and vertical repeatability on the nanometric scale with a large vertical range and high measurement speeds. The basic key to the confocal approach is the use of spatial filtering techniques to eliminate out-of-focus light or glare in specimens in which the thickness exceeds the immediate plane of focus..$^{29}$

There has not been many publication related to the use of Confocal Profilometer Microscopy on anthropological material with the aim of studying butchery related marks and to differentiate them from taphonomic ones. Pante et al. ${ }^{13}$ is one of the recent works which proposes a new systematic and replicable standard for identifying bone surface modifications using high-resolution 3D data. However, there are other projects that have applied the same technology but have focused on differentiating cuts made by stone or by metal tools,$^{30}$ or have used other materials, such as teeth, with more ecological goals. ${ }^{31,32}$ New cranial remains of the Iberian period have recently been described at the site of Puig Castellar (Barcelona, Spain) that show marks related to skinning, the purpose of this study. The areas where the skin scaling action is usually carried out with the scalpel are located in areas with presence of vascular sulcus and cranial sutures. So, must add the proprietary marks of the time during which the remains have been buried. This study aims through a macroscopic, conventional microscopic study and using the Confocal Profilometer Microscopy, first define the marks of vascularization and cranial sutures located in this area that until now have not been described in this type of studies for later and with the use of the measures, as a result of confocal, define the characteristics of each type of mark. Finally, classify the marks that were not classified by visual methods with the functions obtained with confocal analysis.

\section{Material and methods}

\section{Human remains}

The sample analysed in this study was taken from human remains of Puig Castellar, discovered at the beginning of the 20th century and stored in the Museu d'Arqueologia de Catalunya. ${ }^{33}$ Puig Castellar was an Iron Age village to the Laietanii group, an ancient Iberian people, who lived between the fifth century to the second century BC. ${ }^{34}$ The group is characterized by a performed on the dead, preparation of the skull, ${ }^{35}$ perhaps scalping, and skinning and their exhibition seem to have been classical practices among this culture (Figure 1). The study di nuovo of the remains increase the number minimum of the individuals. The set consists of 14 fragments of the jaw and the cranium of at least 12 individuals, two of them correspond a nailed skull (Subirà and Rovira, in press). In the region of temporal fossa it can be observed some vascular impressions, striations of temporal suture, cut marks and taphonomic ones on four of these individuals (Cranium fragments: s.n., 391, 393 and 394) that conserve part of anterior vault (frontal, frontal-parietal) with temporal lines on ectocranial surface. ${ }^{36}$

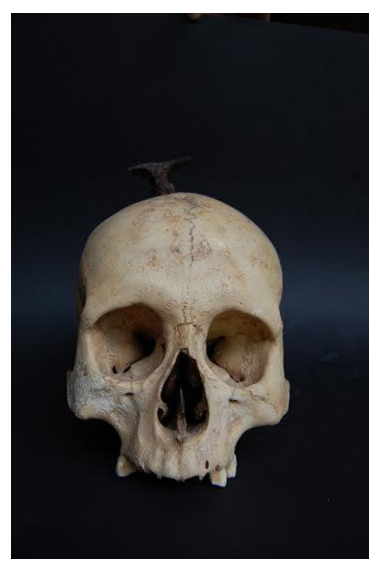

Figure I Nailed skull found in Puig Castellar in 1904.

\section{Imaging measurements}

In order to observe the marks on the bones, optical microscopy was performed using a Leica MZFLIII stereomicroscope (Leica, Wetzlar, 
Germany). Images of each mark have been obtained using a $0.63 \mathrm{x}$ objective and a zoom from $0.8 \mathrm{x}$ to $2.5 \mathrm{x}$, aiming to cover the whole extension of the mark. The images were taken with DC500 digital camera and IM50 software, version 4.0 (Leica Microsystems Imaging Solutions Ltd., Cambridge, United Kingdom). 3D surface imaging of the marks was performed by a Confocal Profilometer, Leica DCM 3D System (Leica Microsystems GmbH, Wetzlar, Germany), with a 5x objective (HCxPL Fluotar). In this mode, the microscope used a light beam with wavelength $\lambda=460 \mathrm{~nm}$ (blue) and the light source was an LED with $5 \mathrm{~W}$ of power. Despite each measured plane being $2.55 \mathrm{x}$ $1.91 \mathrm{~mm} 2$, marks of a larger length were able to be studied due to the stitching function of the microscope. Thus, it allows superimposing, or stitching of the different measured planes, creating a threedimensional image of the whole mark, and generating a complete informative profile. The depth of measurement covered from $400 \mu \mathrm{m}$ to $3500 \mu \mathrm{m}$, depending upon the mark and shape of the bone, whereas length was very variable. The images obtained were then manipulated with the LeicaMap v.6.2 software. They were levelled, a topography layer was extracted from all of them, and rotation and/or correction was performed when required. Whereas rotation is performed in order to facilitate posterior analyses, correction aims to fill blank spaces that can appear due to the height of the area, and does so with information from the surrounding area.

Four profiles were taken from different points of the mark (cranial and caudal, plus two additional points in between), as well as a mean profile of the whole surface obtained by performing a mean of simple profiles that have a distance of $10 \mu \mathrm{m}$ from each other and cover the whole extension of the mark according to Fuentes-Sánchez. ${ }^{30}$ These methodology provide information about the dimensions of the mark in every profile: depth, breadth (canal breadth, breadth at the bottom, and breadth ratio), aperture angle, length, and complexity.

1. Depth: Profundity of the mark (Figure 2)

2. Canal breadth: Width of the mark at the surface perpendicular to the length (Figure 2).

3. Breadth at the bottom: Width of the mark at the bottom (Figure 2).

4. Breadth ratio: Width of the mark at the surface.

5. Aperture angle: Opening angle of the mark (Figure 2).

6. Length: Measurement from end to end of the superficial mark.

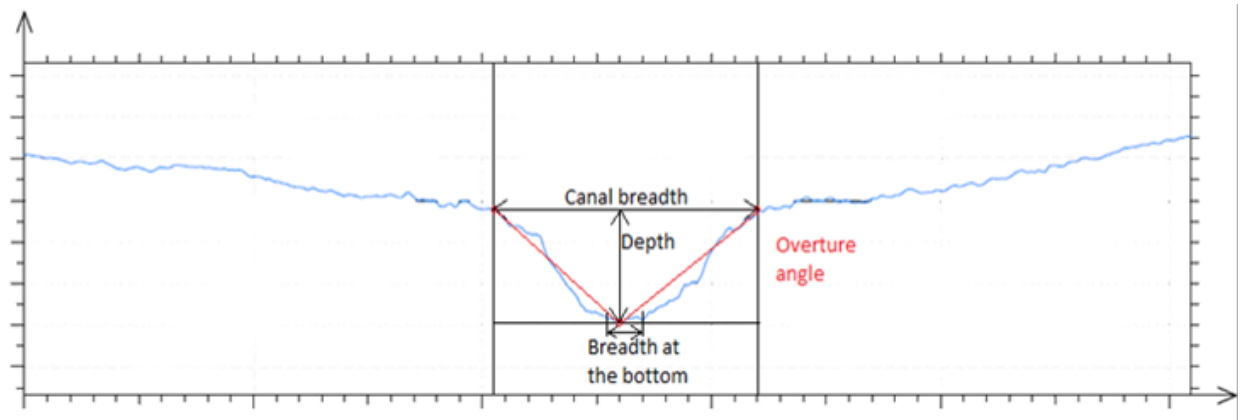

Figure 2 Drawing of the measurements of Canal breadth, Breadth at the bottom, Depth, and Aperture angle.

Canal Breadth, width of the mark at the surface; Breadth at the bottom, width of the mark at the bottom; Depth, depth of the mark; Aperture angle, opening angle of the mark

Complexity is a parameter presented by LeicaMap as a percentage that explains the amount of surface that is deeper than the surrounding area. Thus, high values of this parameter indicate a deeper and more complex pattern of mark. This parameter is thought to be useful because the depth and morphology of the mark should have a characteristic pattern depending upon its source and, in this way, this source could be identifiable through this parameter.

$$
\text { Surface complexity }=(\text { Developed area }- \text { Horizontal area }) \text { Horizontal area } \times 100
$$

Horizontal area: The profile obtained by the mean allow the definition of every kind of marks.

\section{Statistical analysis}

The Saphiro-Wilk normality test was carried out for each of the measurements taken. Based on the results of the normality test, the Student t-test or the Mann-Whitney test was applied to the comparative study between anthropogenic marks, butchery and taphonomic ones. Finally, a discriminant analysis has been applied to obtain the discriminant function that allows differentiating between the marks and allows classifying those that macroscopically could not be assigned. These studies have been carried out using the Past 3.x software $^{37}$ and the IBM SPSS Statistics package version 23. ${ }^{38}$

\section{Results}

\section{Anthropological description}

Detailed macroscopic analyses of the frontal bones of individuals s.n., 391, 393 and 394, allow to observe marks located on the surface of the temporal fossa of the frontal bone. Firstly, marks have been described and classified according to the previously proposed criteria as taphonomic or related to butchery. ${ }^{39,40}$ At the same time two new groups and discrimination criteria, suture related and vascular marks, has been created. Suture related marks share some characteristics with butchery ones, such as their straightness and length, but their location is limited to the area next to a suture, and the V-shape pattern does not appear. On the other hand, vascular ones do not follow a straight path, 
and they become deeper near the origin of the artery, which appears unmistakeable. A total of 52 marks have been observed, and classified according these macroscopic criteria. Of these marks, 21 have been classified as taphonomic, two as suture marks, four as vascular, and
13 have been related to butchery activities. However, there have been 12 marks that cannot be classified due to the fact that they share characteristics of more than one group (Table 1).

Table I Samples analysed from Puig Castellar

\begin{tabular}{lllllll}
\hline Piece & Number of marks & Taphonomic & Butchery related & Vascular & Suture related & Unable to be classified \\
\hline s.n. & 24 & 10 & 4 & 2 & 1 & 7 \\
391 & 19 & 10 & 4 & 2 & & 3 \\
393 & 4 & 1 & 3 & & & \\
394 & 5 & & 2 & & 1 & 2 \\
\hline
\end{tabular}

\section{Imaging description}

Confocal Profilometer Microscopy provides us with quantifiable parameters such as depth, length, and aperture angle among others. These parameters have been studied in order to describe differences between the four kinds of marks. On the one hand, differences can be seen in the measurements of depth, length, and complexity, while canal breadth, breadth at the bottom, breadth ratio, and aperture angle, display similar values in all of them and do not show differences (Table 2):

Table 2 Mean values of the descriptive characters obtained using Leica DCM 3D

\begin{tabular}{|c|c|c|c|c|c|c|c|c|}
\hline $\begin{array}{l}\text { Kind of } \\
\text { mark }\end{array}$ & $\mathbf{n}$ & $\begin{array}{l}\text { Canal } \\
\text { breadth }\end{array}$ & $\begin{array}{l}\text { Breadth at the } \\
\text { bottom }\end{array}$ & $\begin{array}{l}\text { Breadth } \\
\text { ratio }\end{array}$ & Depth & $\begin{array}{l}\text { Aperture } \\
\text { angle (o) }\end{array}$ & $\begin{array}{l}\text { Length } \\
(\mathrm{mm})\end{array}$ & $\begin{array}{l}\text { Complexity } \\
(\%)\end{array}$ \\
\hline Butchery & 13 & $403.7 I \pm|4| .42$ & $103.42 \pm 68.43$ & $26.54 \pm 16.13$ & $86.78 \pm 44.42$ & $135.46 \pm 20.39$ & $3.1 \pm 1.47$ & $478.83 \pm 116.11$ \\
\hline Taphonomi c & 21 & $349.32 \pm 164.18$ & $82.67 \pm 38.92$ & $29.34 \pm 17.91$ & $56.88 \pm 32.17$ & $140.88 \pm 26.72$ & $4.21 \pm 1.91$ & $37 I \pm 125.04$ \\
\hline Vascular & 4 & $437.4 I \pm 192.9 \mid$ & $112.05 \pm 104.93$ & $22 \pm 12.91$ & $121.02 \pm 49.55$ & $127.1 \mid \pm 9.95$ & $1.45 \pm 0.65$ & $598.09 \pm 117.88$ \\
\hline Suture & 2 & $375.16 \pm 126.77$ & $86.32 \pm 46.95$ & $22.16 \pm 5.03$ & $63.71 \pm 60.03$ & $152.32 \pm 20.23$ & $4.6 \pm 0.99$ & $270.67 \pm 99.14$ \\
\hline
\end{tabular}

*Unless indications, all the measurements are on micrometres

1. Canal breadth: none of the marks display more than $0.5 \mathrm{~mm}$ of breadth and all of them round the $400 \mu \mathrm{m}$ without differences at first sight.

2. Breadth at the bottom: butchery and vascular marks are grouped together with a value around $0.1 \mathrm{~mm}$, and taphonomic and suture related marks with a value of $85 \mu \mathrm{m}$. However, both groups display a wide standard deviation that makes them overlap each other.

3. Breadth ratio: it is presented as the relationship between canal breadth and breadth at the bottom and ca. $25 \mu \mathrm{m}$ in all marks.

4. Aperture angle: it ranges from 1250 to 160 o in the groups, showing an overlapping.

5. Depth: vascular marks show the deepest cut $(121 \mu \mathrm{m})$, followed by butchery $(87 \mu \mathrm{m})$, then suture related $(64 \mu \mathrm{m})$, and finally taphonomic marks $(57 \mu \mathrm{m})$. Thus, differences can be appreciated between the groups, even though some values overlap.

6. Length: vascular marks display the shortest cut $(1.45 \mathrm{~mm})$, followed by butchery $(3 \mathrm{~mm})$, then taphonomic $(4.2 \mathrm{~mm})$, and finally suture related marks $(4.5 \mathrm{~mm})$. Taphonomic marks also have the greatest variance, overlapping with both butchery and suture related marks.

7. Surface complexity: The complexity is representative of the visual impact of the mark. It is the additional developed area compared to the horizontal area and expressed as a percentage of the horizontal area. This, at first sight, shows the greatest differences between groups. Vascular marks have the greatest complexity $(600 \%)$, followed by butchery $(480 \%)$, taphonomic $(370 \%)$, and finally suture related marks $(270 \%)$.

Each type of mark also has a clear, unique profile and 3D image: Butchery related (Figure 3A): depth is the most remarkable characteristic of this kind of mark $(60-140 \mu \mathrm{m})$. A sharp or open V-shape is perceptible. Taphonomic (Figure 3B): no informative profile can be obtained. The depth of the mark is very small $(<80 \mu \mathrm{m})$, and can be missed as part of the surface. Vascular (Figure 4A): depth is also the most remarkable characteristic $(80-170 \mu \mathrm{m})$, and a U-shape is clearly perceptible. Suture related (Figure 4B): it also has a visible V-shape. However the mark is less deep than a butchery mark $(<80 \mu \mathrm{m})$, and the surface is more irregular. Table 2 only shows the values of the mean profile as generated by LeicaMap. Nevertheless, profiles at different points of each mark have also been generated. It has to be mentioned that it has not been possible in all the cases to generate informative profiles. Therefore, it should be stated that for butchery related marks, up to $65 \%$ of the profiles obtained were informative, whereas less than $50 \%$ of the profiles for taphonomic marks were deemed to be useful. As already mentioned, the aim of this study was to differentiate taphonomic and butchery marks with Leica DCM 3D.The comparison was focused on these, because vascular marks are very easily identifiable at first sight and, as has previously stated, the suture related ones are limited to a specific region of the bones. In the parameter set studied, only the measurements of depth and complexity shown a significant differences $(\mathrm{p}<0.05)$ between groups (Table 3 ). 

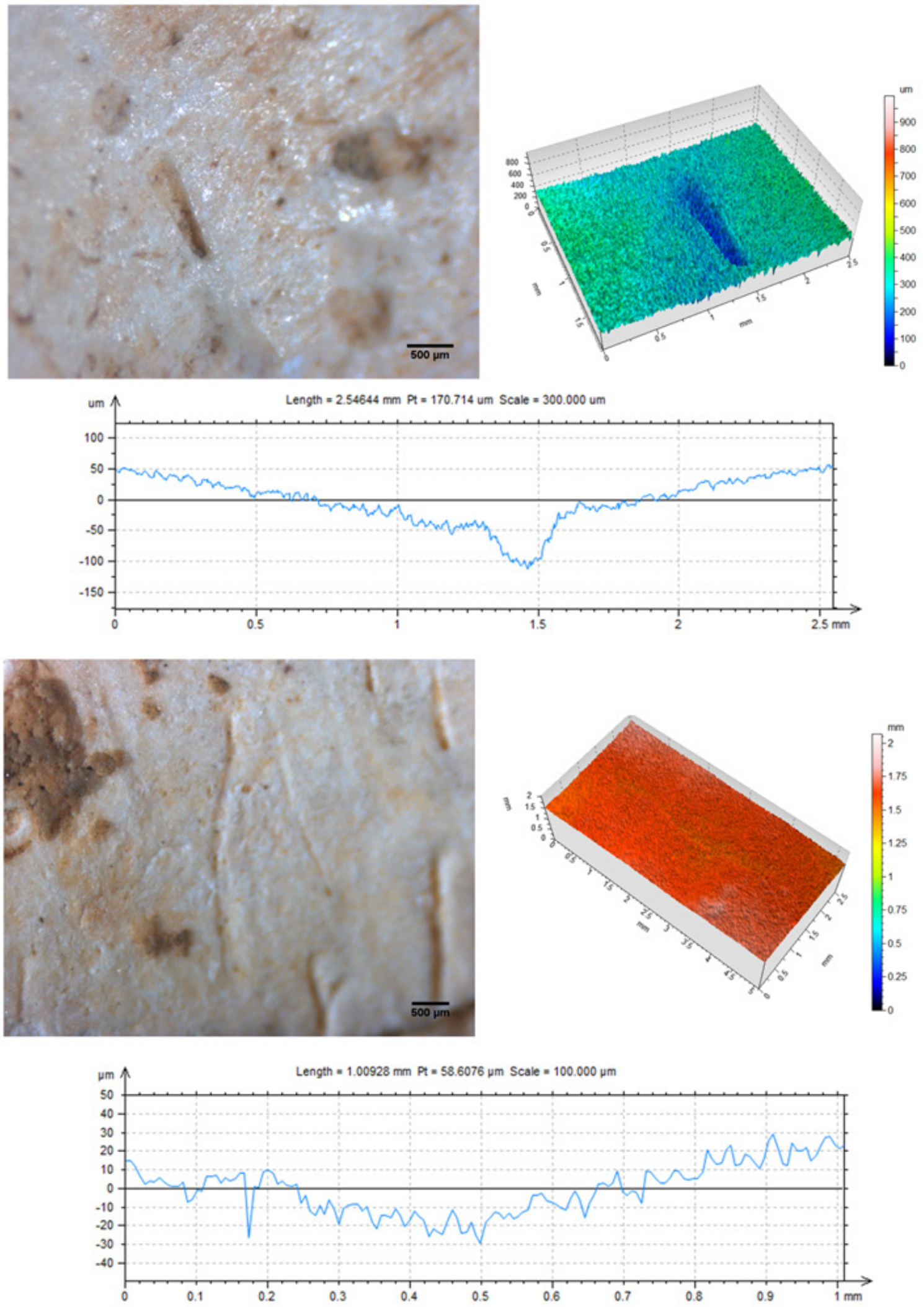

Figure 3 Up, Butchery related mark (skull 39I): optical microscopy photography, 3D representation, and main profile obtained. Down, taphonomic mark (skull s.n.): optical microscopy photography, 3D representation, and main profile obtained. 

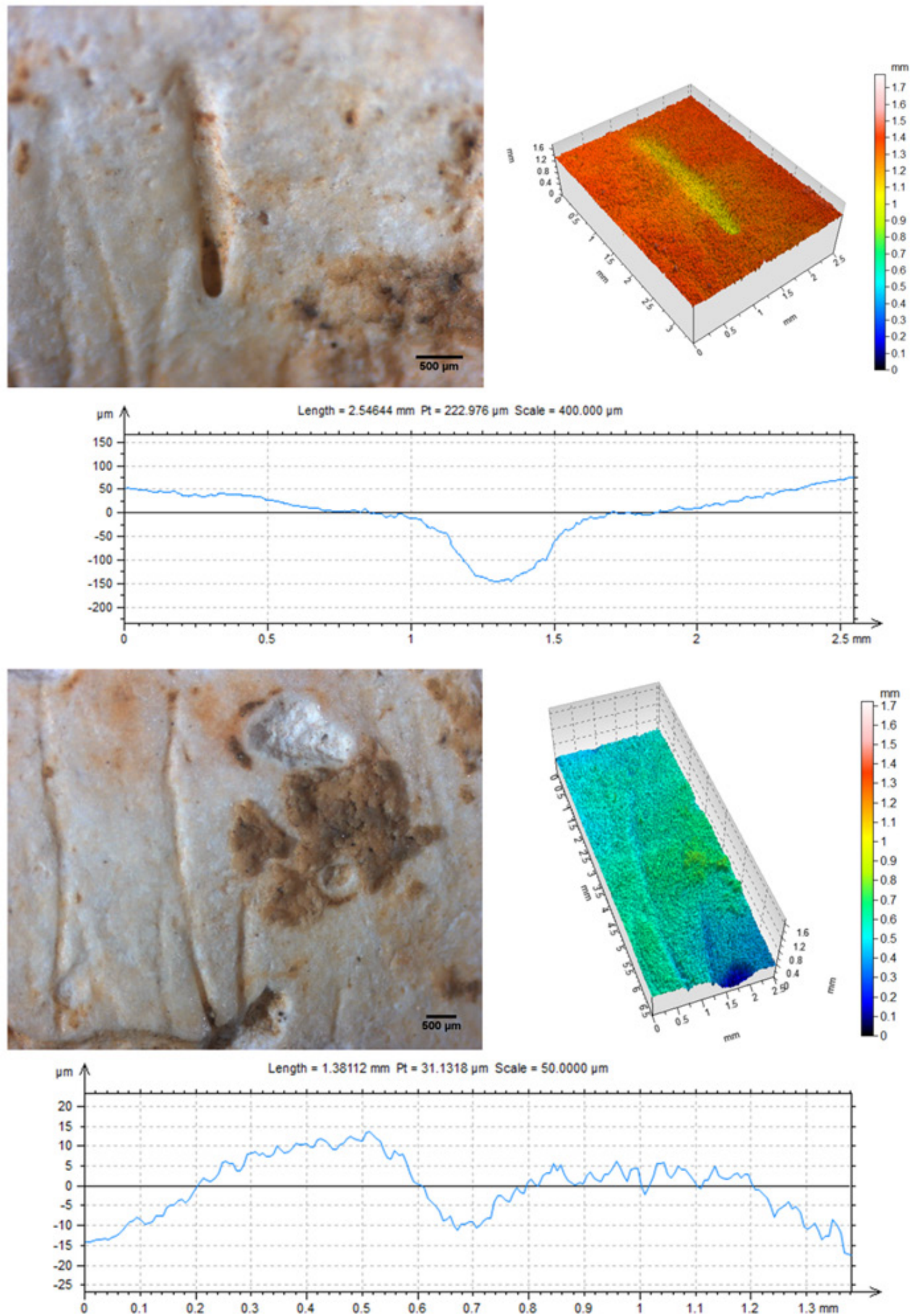

Figure 4 Up, vascular mark (skull s.n.): optical microscopy photography, 3D representation, and main profile obtained. Down, suture related mark (skull s.n.): optical microscopy photography, 3D representation, and main profile obtained. 
Thus, the study has shown that only the measurements of depth and complexity show significant differences between groups (Table 3 ), the values of butchery related marks being greater. Nevertheless, only depth appears to be significant and useful when a discriminant analysis is performed using all parameters (Table 4). After that, a discriminant analysis using all parameters was performed in order to evaluate their robustness. If the function obtained appears to be useful, it could be applied on the marks that could not be classified through macroscopically methods in the first place. Despite that, the discriminant function obtained only correctly re-classifies $65.4 \%$ of the sample (Table 5).

Table 3 Statistical tests performed on the measurements showed in Table 2 between butchery and taphonomic marks

\begin{tabular}{|c|c|c|c|c|c|c|c|c|}
\hline & & Sa & iro-wil & est & t-test & & Mann- & ney test \\
\hline & & $\mathbf{N}$ & value & $\mathbf{p}$ & value & $\mathbf{p}$ & value & $\mathbf{p}$ \\
\hline 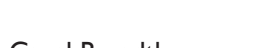 & Butchery & 10 & 0.87 & 0.099 & 0.865 & 0.396 & -0.818 & 0.413 \\
\hline Canlar Dreaun & Taphonomic & 16 & 0.942 & 0.378 & & & & \\
\hline D & Butchery & 10 & 0.876 & 0.118 & 0.99 & 0.332 & -0.712 & 0.476 \\
\hline Breadth at the Bottom & Taphonomic & 16 & 0.921 & 0.173 & & & & \\
\hline 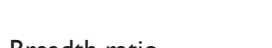 & Butchery & 10 & 0.949 & 0.657 & -0.403 & 0.691 & -0.29 & 0.772 \\
\hline Dieaurit ratio & Taphonomic & 16 & 0.937 & 0.313 & & & & \\
\hline $\mathrm{R}_{\mathrm{m}}$ & Butchery & 10 & 0.867 & 0.093 & 1.992 & 0.058 & -2.082 & $0.037^{* *}$ \\
\hline Depur & Taphonomic & 16 & 0.837 & $0.009 *$ & & & & \\
\hline A - & Butchery & 10 & 0.911 & 0.285 & -0.544 & 0.592 & -1.082 & 0.279 \\
\hline Faper ture dilgie & & 15 & 0.814 & $0.006 *$ & & & & \\
\hline $1+25+5$ & Butchery & 10 & 0.853 & 0.063 & -1.598 & 0.121 & -1.518 & 0.129 \\
\hline & Taphonomic & 20 & 0.96 & 0.549 & & & & \\
\hline & Butchery & 11 & 0.894 & 0.157 & 2.354 & $0.026^{* *}$ & -2.209 & $0.027 * *$ \\
\hline Comprexicy & Taphonomic & 20 & 0.932 & 0.17 & & & & \\
\hline
\end{tabular}

*: the sample does not a normal distribution. **: significant differences between groups

Table 4 Summary of the results of the discriminant analysis performed by SPSS Statistics

\begin{tabular}{lll}
\hline Wilks' Lambda (p-value) & Discriminant function & Discriminant values $(\mathbf{X})$ \\
\hline $0.842(0.55)^{*}$ & $=-1.894+0.027 \quad \mathrm{~h}$ & Butchery: 0.535 \\
& & Taphonomic: $-0.32 \mathrm{I}$ \\
\hline
\end{tabular}

*: not significant

Table 5 Re-grouping of the sample using the discriminant function generated

\begin{tabular}{|c|c|c|c|c|c|}
\hline & & \multirow{2}{*}{ Visual classification } & \multicolumn{2}{|c|}{ Predicted group correspondence } & \multirow[t]{2}{*}{ Tota } \\
\hline & & & Butchery & Taphonomic & \\
\hline \multirow{2}{*}{ Original } & \multirow{2}{*}{ Re-counting } & Butchery & 5 & 5 & 10 \\
\hline & & Taphonomic & 4 & 12 & 16 \\
\hline
\end{tabular}

\section{Discussion}

This study has focused on comparing a previous method based on macroscopic and microscopic features ${ }^{39,40}$ with the new methodology provided by Leica DCM 3D and innovations and improvements that it comports. With this aim, we have used a sample for which the marks had yet to be classified instead of bones on which experimental cuts and trampling had been performed, such as those studied by DomínguezRodrigo et al., ${ }^{40}$ Bonney, ${ }^{20}$ and Fuentes-Sánchez. ${ }^{30}$ Knowing that, it becomes clear that the new application is dependable on the old one in this study. So, the results shown described quantitative characteristics of the different groups classified according previous criteria and explain whether the new technique relates and coincides with the old one. The statistical values of each mark have been used for the analysis. These data have been obtained by the LeicaMap software, and are calculated as a mathematical mean of several profiles of the mark, as it has been stated before. The profiles have a high dependence on the conservation of the surface. Therefore, it is difficult to obtain informative profiles when the surface is irregular or damaged and the 
studied mark is not very deep. Due to the damage on the surface of our samples, it was difficult to obtain useful profiles on some of the marks. When the analysis is performed on all the marks, the simple, informative profiles obtained of the vascular and butchery ones show a greater depth on all measured points. These results also show a greater depth when the caudal point is approached in both kind of marks.

It has to be remembered that, when marks have been studied with Leica DCM 3D, the aim has been to differentiate only between taphonomic and butchery marks. The study has focused on these, because vascular marks are very easily identifiable at first sight and the suture related ones are limited to a specific region of the bones, as it has been stated before. Also, further studies may use experimental cut marks for which the nature is known in advance, in order to describe differences between kinds of marks. In order to improve these results and the reliability of the technique, more parameters may be taking into account. The measurements of the distal ends can also be very useful, since the average tend to homogenize the values. Then, when differences on the kind of marks are focused, their study has shown that only the measurements of depth and complexity show significant differences between groups (Table 3), being greater the values on butchery related marks. Nevertheless, only depth appears to be significant and useful when a discriminant analysis is performed (Table 4). The discriminant function obtained reclassifies correctly $65.4 \%$ of the sample (Table 5). When the same function is applied to the macroscopically unclassified marks, 7 out of 12 marks (58.3\%) have been able to be classified, 3 as butchery and 4 as taphonomic marks.

Finally, with the regard technology used, the confocal microscopy is a non-invasive technique with minimal manipulation of sample obtaining microscopic details in the marks that reflect the tools that used to generate them. A new study using experimental cut marks would improve the potential and reliability of this technique, since knowing the true nature of the marks in advance, no error would be made and the real differences between groups could be discerned. Thus, the methodology appears to be very promising that could allow the standardization the identification of bone surface modifications and providing a reliable quantifiable assessment, with the elaboration of research databases. However, the confocal microscope also has a limitation regarding the shape and size of the sample. Bone fragments can typically have larger dimensions, curvature, and thickness that make them difficult to study. When an analysis is made of these types of samples, it is necessary to work with special objectives of greater depth of field and the implementation of a system for placement of the sample that allows the area of interest to be analysed without having to move it. In order to obtain an informative profile, the bone is placed on a sand box that stabilises it, and enables us to choose the position with a mark that has to be parallel to the plane so as to obtain the maximal depth, and so that the gradient of the mark appears more accurate.

In summary, the 3D surface profilometry technique may constitute an interesting complementary method currently used in anthropology studies. This technique provides a robust methodology for a noncontact, real-time 3D image, allowing the quantification of the volume studied. This technique, together with traditional techniques already used in the field of anthropology, will allow a complete study of marks made in ancient human remains, providing additional information to facilitate the interpretation of results. In years to come 3D surface profilometry should be expected to become one of the most rapidly developing and exceptionally dynamic optical measurement techniques used extensively in studies of anthropology. At the same time, it is a non-destructive methodology that can generate a database of access to researchers and is applicable to material of small dimensions up to now. ${ }^{41}$

\section{Acknowledgments}

The authors wish to thank the Museu d'Arqueologia de Catalunya and Carme Rovira Hortala for providing the sample that has been studied in this project, and also the Scientific and Technical Services of Universitat Autònoma de Barcelona for their technical advice. We also thank Óscar Rodríguez (Leica Microsystems) for technical information.

\section{Conflicts of interest}

Author declares that there is no conflict of interest.

\section{Funding}

My research project there isn't sponsored.

\section{References}

1. Binford LR. Faunal remains from Klasies River mouth. New York: Acadmic Press; 1984.

2. Shipman P. Life history of a fossil: an introduction to taphonomy and paleoecology. Cambridge: Harvard University. 1981

3. Villa P. Conjoinable pieces and site formation processes. American antiquity. 1982;47:276-290.

4. Scott JE, Marean CW. Paleolithic hominin remains from Eshkaft-e Gavi (southern Zagros Mountains, Iran): description, affinities, and evidence for butchery. J Hum Evol. 2009;57:248-259.

5. Solari Giachino A. Identificación de huellas de manipulación intencional en restos óseos humanos de origen arqueológico. Universidad de Granada: Ph.D. dissertation, Departamento de Ciencias Morfológicas; 2010.

6. Olsen SL, Shipman P. Surface modification on bone: Trampling versus butchery. J Archaeol Sci. 1988;15(5):535-553.

7. Greenfield HJ. The Origins of Metallurgy: Distinguishing Stone from Metal Cut-marks on Bones from Archaeological Sites. Journal of Archaeological Science. 1999;26(7):797-808.

8. Greenfield HJ. Slicing cut marks on animal bones: diagnostics for identifying stone tool type and raw material. Journal of Field Archaeology. 2006;31(2):147-163.

9. Smith MJ, Brickley MB. Animals and interpretation of flint toolmarks found on bones from West Tump Long Barrow, Gloucestershire. Int $J$ Osteoarchaeol. 2004;14(1):18-33.

10. Lewis JE. Identifying sword marks on bone: criteria for distinguishing between cut marks made by different classes of bladed weapons. $J$ Archaeol Sci. 2008;35(7):2001-2008.

11. Juana de S, Galán AB, Domínguez-Rodrigo M. 2010. Taphonomic identification of cut marks made with lithic handaxes: an experimental study. J Archaeol Sci. 37(8):1841-1850.

12. Courtenay L1 A, Maté-González MA, Aramendi J, et al. Testing accuracy in 2D and 3D geometric morphometric methods for cut mark identification and classification. Peer J. 2018;6:e5133.

13. Pante MC, Muttart MV, Keevil TL, et al. A new high-resolution 3-D quantitative method for identifying bone surface modifications with implications for the Early Stone Age archaeological record. J Hum Evol. 2017; $102: 1-11$ 
14. Otárola-Castillo E, Torquato MG, Hawkins HC, et al. Differentiating between cutting actions on bone using 3D geometric morphometrics and Bayesian analyses with implications to human evolution. J Archaeol Sci. 2018;89:56-67.

15. Fernández-Jalvo Y, Carlos Díez J, Cáceres I, et al. Human cannibalism in the Early Pleistocene of Europe (Gran Dolina, Sierra de Atapuerca, Burgos, Spain). J Hum Evol. 1999;37(3-4):591-622.

16. Saladié P, Huguet R, Rodríguez-Hidalgo A, et al. Intergroup cannibalism in the European Early Pleistocene: the range expansion and imbalance of power hypotheses. J Hum Evol. 2012;63(5):682-695.

17. Boulestin B, Zeeb-Lanz A, Jeunesse C, et al. Mass cannibalism in the Linear Pottery Culture at Herxheim (Palatinate, Germany). Antiquity. 2015;83(322):968-982.

18. Agustí B, Díaz-Carvajal A, De Prado G. Public Exhibition of Heads and Weapons among the Iberians of the North. Dossiers d'Archéologie. 2015;367:32-37.

19. Agustí B, Codina F, Díaz-Carvajal A, et al. The practice of severed heads attested in Ullastret (Catalonia). New data, new readings. In: Claire-Anne de Chazelles, Martine Schwallerarts, et al. Hors-série. 2016;7(2):599-611.

20. Bonney H. An investigation of the use of discriminant analysis for the classification of blade edge type from cut marks made by metal and bamboo blades. Am J Phys Anthropol. 2014;154(4):575-584.

21. Domínguez-Rodrigo M, Juana de S, Galán AB, et al. A new protocol to differentiate trampling marks from butchery cut marks. J Archaeol Sci. 2009;36(12):2643-2654.

22. Fernández-Jalvo Y, Andrews P. Atlas of Taphonomic Identifications. Springer. 2016.

23. Bello SM, Soligo C. A new method for the quantitative analysis of cutmark micromorphology. J Archaeol Sci. 2008;35(6):1542-1552.

24. Bartelink EJ, Wiersema JM, Demaree RS. Quantitative analysis of sharpforce trauma: an application of scanning electron microscopy in forensic anthropology. J Forensic Sci. 2001;46(6):1288-1293.

25. Schroettner H, Schmied M, Scherer S. Comparison of 3D surface reconstruction data from certified depth standards obtained by SEM and an Infinite Focus Measurement Machine (IFM). Microchim Acta. 2006;155:279-284.

26. Bello SM, De Groote I, Delbarre G. Application of 3-dimensional microscopy and micro-CT scanning to the analysis of Magdalenian portable art on bone and antler. J Archaeol Sci. 2013;40(5):2464-2476.

27. During EM, Nilsson L. Mechanical surface analysis of bone: a case study of cut marks and enamel hypoplasia on a Neolithic cranium from Sweden. Am J Phys Anthropol. 1991;84:113-125.

28. Kaiser TM, Katterwe H, Burke A. The apllication of 3D-microprofilometry as a tool in the surface diagnosis of fossil and sub-fossil vertebrate hard tissue. An example from the Pliocene Upper Laetolil Beds, Tanzania. Int J Osteoarchaeol. 2001;11(5):350.
29. Claxton NS, Fellers TJ, Davidson MW. Laser Scanning Confocal Microscopy. In: Webster JG, editor. Encyclopedia of Medical Devices and Instrumentation. New Jersey: John Wiley \& Sons, 2006. p. 1-37.

30. Fuentes-Sánchez D. Caracterización de marcas de corte mediante el perfilómetro láser confocal. Unpublished MSc. Thesis, Máster Universitario en Evolución Humana, Universidad de Burgos y Universidad de Alcalá. 2014.

31. Scott RS, Ungar PS, Bergstrom TS, et al. Dental microwear texture analysis shows within-species diet variability in fossil hominins. Nature. 2005;436(7051):693-695.

32. Evans AR. Shape descriptors as ecometrics in dental ecology. Hystrix, Ital J Mammal. 2013;24(1):133-140.

33. Subirà ME, Rovira C. Las "cabezas cortadas" del poblado ibérico del Puig Castellar (Sta Coloma de Gramanet, Barcelona). Trabajos de Prehistoria: Datos para una reinterpretacion; 2019.

34. Pinta de la JL, Rio-Miranda J. El poblado Layetano de Puig Castellar, Santa Coloma de Gramenet (Barcelona). Santa Coloma de Gramenet: Museu Municipal Puig Castellar. 1981.

35. Clavell M, Manzano A, Marín S, et al. Puig Castellar. Santa Coloma de Gramenet. Guides Archeology Museum of Catalonia. 2007.

36. Subirà ME. Estudi antropològic de les restes de Puig Castellar dipositades al Museu d'Arqueologia de Catalunya. Informe antropológico. Bellaterra: Museu d'Arqueologia de Catalunya, Universitat Autònoma de Barcelona; 2014.

37. Hammer $\varnothing$, Harper DAT, Ryan PD. PAST: Paleontological statistics software package for education and data analysis. Palaeontol Electron. 2001;4(1):9.

38. IBM Corp. IBM SPSS Statistics for Windows, Version 23.0. NY: Armonk, IBM Corp; 2015.

39. Bello SM, Parfitt SA, Stringer C. Quantitative micromorphological analyses of cut marks produced by ancient and modern handaxes. $J$ Archaeol Sci. 2009;36(9):1869-1880.

40. Domínguez-Rodrigo M, Pickering TR, Bunn HT. Experimental study of cut marks made with rocks unmodified by human flaking and its bearing on claims of 23 .4-million-year-old butchery evidence from Dikika, Ethiopia. J Archaeol Sci. 2012;39(2):205-214.

41. Bello SM. New Results from the Examination of Cut-Marks Using Three-Dimensional Imaging. In: Ashton N, Lewis S, Stringer C, editors. The Ancient Human Occupation of Britain, Vol. 14. London: Elsevier Developments in Quaternary Sciences; 2011. p. 249-262. 